\title{
Mariátegui y el problema de la autonomía literaria: a propósito de la recepción de la literatura rusa
}

\section{Mariátegui and the problem of literary autonomy: the reception of Russian literature}

\author{
Martín Salinas \\ Universidad de Buenos Aires \\ Universidad Nacional Arturo Jauretche \\ (Argentina) \\ magallanes929@yahoo.com.ar
}

El artículo analiza la recepción de la literatura rusa por parte de José Carlos Mariátegui durante la década de 1920. La consumación de la Revolución Rusa supone, para la lectura de Mariátegui, un cambio de época que implica no solo un punto de giro en lo que respecta a la vida política y económica de Rusia, sino que también representa la corroboración de la inminente debacle del proceso civilizatorio burgués y, sobre todo, la posibilidad de una perspectiva revolucionaria en Perú. La centralidad que, en el marco de la crítica cultural, adquiere el análisis de fenómenos literarios, se advierte tanto en los estudios referidos a las vanguardias europeas como al incipiente realismo al que daría lugar la continuidad del proceso revolucionario bolchevique. Las intervenciones críticas de Mariátegui en el proceso que se abre con la revolución, por lo tanto, dan cuenta de una reinterpretación de la historia entendida como un proceso abierto, en el que el testimonio de parte se articula con la propuesta política.

Palabras Clave: Marxismo - Crítica literaria - Realismo - Vanguardias - Literatura nacional 


\begin{abstract}
This paper analyses José Carlos Mariátegui's reception of Russian literature during the 1920s. For Mariátegui, the Russian Revolution brings about a change of times which implies not only a turning point as regards Russia's political and economic life but also the confirmation of the imminent failure of the bourgeois civilizing process and, above all, the possibility of a revolutionary perspective in Peru. The relevance of literary analysis, within the framework of cultural criticism, can be noticed in studies related to European Avant-gardism as well as the incipient Realism in the continuity of the Bolshevik revolutionary process. Mariátegui's critical interventions in the process introduced by the Revolution, therefore, shows a reinterpretation of history as an open process, in which the individual point of view interacts with the political project.
\end{abstract}

Key Words: Marxism - Literary Criticism - Realism - Avant-garde - National literature

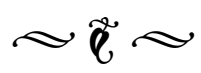

Literatura y política conforman dos polos complementarios en la perspectiva que Mariátegui elabora en torno a la Revolución Rusa como alternativa a la crisis de la sociedad burguesa de principios de siglo $\mathrm{XX}$. Así como la recepción de la literatura rusa incide de una manera significativa en la conformación de una imagen de las políticas revolucionarias que, a través de Europa, promueven una relectura de la situación política del Perú, la misma literatura es evaluada de acuerdo a los parámetros que establece el acontecimiento revolucionario como centro nodal del cambio histórico. La afinidad electiva ${ }^{1}$ que Mariátegui advierte

1. "Designamos por 'afinidad electiva' un tipo particular de relación dialéctica que se establece entre dos configuraciones sociales o culturales, que no es reductible a la determinación casual directa o a la 'influencia' en sentido tradicional. Se trata, a partir de una cierta analogía estructural, de un movimiento de convergencia, de atracción recíproca, de confluencia activa, de combinación capaz de llegar hasta a la fusión”. LÖWY, Michael, Redención y utopia. El judaísmo libertario en Europa Central. Un estudio de afinidad electiva (traducción entre ambos polos establece una compleja correspondencia entre la configuración literaria y la constitución política, en la que se reconoce el carácter problemático de la autonomía de la conformación literaria. Si, por un lado, en la aplicación metodológica de una correspondencia fundada en la afinidad electiva ofrece como resultado un cuadro en el que se perciben rasgos característicos de un voluntarismo estético y político, que expresan más las expectativas subjetivas que las realizaciones concretas en las esferas mencionadas; por otro lado, le permite a Mariátegui evadirse de la lecturas históricas lineales, que hacen del desarrollo social, pero también del literario, un recorrido de dirección única. La concepción de la historia como un campo de fuerzas contradictorias, en cuyo marco se dirimen las corrientes históricas, se encuentra en la base del pensamiento de Mariátegui, para quien la disputa ideológica

de Horacio Tarcus), El cielo por asalto, Buenos Aires, 1997, p. 9. 
da cuenta de una concepción de la historia como un proceso abierto. El siguiente artículo se organiza, entonces, en tres secciones en las que se intenta: 1) ofrecer una lectura de la concepción literaria que define la posición e intervención de Mariátegui en el proceso histórico y literario del Perú; 2) analizar el debate político que ha despertado su interpretación literaria y 3) colocar en perspectiva su interpretación de la nueva literatura rusa, sobre todo, respecto de la diferencia que guarda con la promoción oficial del realismo socialista en la Unión Soviética.

\section{Testimonio de parte en el proceso de la literatura}

En las primeras páginas del capítulo más extenso de Siete ensayos de interpretación de la realidad peruana (1928), "El proceso de la literatura",Mariátegui exhibe los presupuestos teóricos y metodológicos de su interpretación de la historia de la literatura peruana y de la relación entre política y arte que condiciona su posición como intelectual y crítico literario. En tanto intérprete comprometido con el objeto de estudio, su "testimonio de parte" destaca como parámetro de análisis lo que ya se anuncia en el título del capítulo: se trata de un proceso que, en "su acepción judicial", se encuentra en pleno desarrollo, y dentro del cual, su posición partidaria, lejos de limitarse a registrar su despliegue desde fuera, supone una toma de partido, una tentativa por intervenir en el proceso: "Me propongo, sólo, aportar mi testimonio a un juicio que considero abierto". ${ }^{2}$

2. MARIÁTEGUI, José Carlos, Siete ensayos de interpretación de la realidad peruana (estudio preliminar de María Pía López), Gorla, Buenos Aires, 2005, p. 177.
El hecho de que, en el proceso de la historia de la literatura peruana, el testimonio de parte de Mariátegui se encuentre atravesado por condicionamientos políticos y religiosos explícitos convierte sus intervenciones en la postulación de una historia alternativa a la historiografía burguesa imperante en el Perú, y en cuanto tal, en una crítica de la tradición (“...mi visión ante el pasado parece ser la de votar en contra" $\left.{ }^{\prime}\right)$. Como construcción de una interpretación alternativa, sus declaraciones se cargan de un sentido fundacional, desde el cual se aboga por el rescate de un pasado irredento del ocultamiento al que han sido sometidos los sectores segregados y oprimidos. En el caso de Latinoamérica, el punto de inflexión lo constituye la conquista: "La Conquista trasplantó al Perú, con el idioma español, una literatura ya evolucionada". ${ }^{4}$ La interpretación que hace de la literatura peruana un eslabón de la cadena que, a través de la conquista, parte de la literatura española, establece una línea de continuidad que deja de lado el hecho, fundamental, de que "... la actual sociedad peruana tiene el pecado original ... de haber nacido y haberse formado sin el indio y contra el indio". ${ }^{5} \mathrm{La}$ complementación de una intervención que apunta al futuro rastreando el pasado es la que le otorga a la participación en el proceso de la historia de la literatura de Mariátegui la cualidad del rostro de Jano, que avizora un porvenir, en la misma medida en que atestigua la catástrofe sobre la que se construye el presente. En este sentido, la interpretación histórica de Mariátegui mantiene una afinidad electiva con la lectura

\section{Ibídem.}

4. Ídem, p. 183.

5. MARIÁTEGUI, José Carlos, "El hecho económico en la historia peruana", en Obras, 2 volúmenes, Casa de las Américas, La Habana, 1982, p. 299. 
de Walter Benjamin, para quien no hay posibilidad de un futuro sin sometimiento mientras el pasado no sea rescatado de la opresión cotidiana a la que es sometido por la concepción histórica representada por el positivismo economicista propio de la II Internacional. ${ }^{6}$ En efecto, la propuesta de la Alianza Popular Revolucionaria Americana (en adelante APRA) de constituir un frente anti-imperialista en el que los sectores burgueses se fusionen con el campesinado, constituye, para Mariátegui, una posición tendiente a reforzar una continuidad histórica bajo la cual el campesinado es constantemente oprimido. El análisis de una literatura indigenista, umbral de la literatura indígena, en este sentido, supone el rescate de una tradición que mantiene su potencial crítico. En sus tesis "Sobre el concepto de la historia", Benjamin ha expuesto una imagen que resulta afín a la lectura que el autor de $L a$ escena contemporánea elaborara en la década de 1920:

E1 peligro amenaza tanto al acervo de la tradición como a sus receptores. Para ambos, el peligro es uno y el mismo: convertirse en instrumento de la clase dominante. En cada época hay que intentar sustraer a la tradición del conformismo $\mathrm{y}$, de ese modo, superarla... Ni siquiera los muertos estarán a salvo del enemigo, cuando él venza. Y este enemigo no ha cesado de vencer. $^{7}$

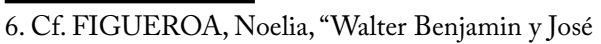
Carlos Mariátegui: gestos para refundar una teoría crítica subalterna”, en Herramienta, Buenos Aires, 2012, No 51, pp. 53-68; también KOHAN, Néstor, De Ingenieros al Che. Ensayos sobre el marxismo argentino y latinoamericano, Instituto Cubano de Investigación Cultural Juan Marinello, La Habana, 2008, pp. 113-128.

7. BENJAMIN, Walter, "Sobre el concepto de historia" (traducción de Tomás Joaquín Bartoletti y Julián Fava), 138
En este sentido, la perspectiva de Mariátegui se caracteriza por una congregación de historicidades que confluyen en el presente histórico. En la aplicación de esta metodología de interpretación, y de intervención, la presencia de la Revolución Rusa y de la literatura que se produce en su órbita adquiere una relevancia particular en el pensamiento de Mariátegui. Como expresión de la afinidad electiva que éste establece entre el proceso revolucionario que observa en la Unión Soviética y la perspectiva revolucionaria que impulsa en sus intervenciones para la realidad peruana, se encuentra el reconocimiento de la distancia que tanto la Unión Soviética como Perú mantienen respecto de la tradición occidental. Mariátegui advierte que Rusia oscila "entre Oriente y Occidente", pero que "desde hace algún tiempo los ojos de Rusia, un poco desencantados de las muchedumbres de Europa, se vuelven, iluminados y proféticos, a los pueblos de Asia". ${ }^{8}$ La situación de Perú guarda una relación, por cierto no lineal, con esta distancia que Rusia mantiene respecto de la historia de occidente; tal como lo expresa en el "Esquema de la evolución económica" de Siete ensayos de interpretación de la realidad peruana, el desarrollo de Perú manifiesta una peculiaridad que lo diferencia "de otros pueblos de Sudamérica": "E1 Perú se encontraba a una enorme distancia de Europa... Por su situación geográfica, el Perú resultaba más vecino y más cercano al Oriente". ${ }^{9}$ Esta relación, desde la lectura histórica de Mariátegui, es interrumpida por la intervención occidental que se realiza con

en Estética y politica, prefacio de Ralph Buchenhorst, Las Cuarenta, Buenos Aires, 2009, p. 142.

8. Ídem, p. 149.

9. MARIÁTEGUI, José Carlos, Siete ensayos..., Op. Cit., p. 24. 
la conquista. En el reconocimiento de esta afinidad electiva, Mariátegui establece una relación histórica que no se aviene con un concepto de progreso lineal que presupone un modelo de desarrollo histórico preestablecido. En ese sentido, Mariátegui ubica

...a Perú fuera de la órbita occidental, al mismo tiempo que lo caracteriza como una formación social más cercana en realidad a Oriente. Una vez que cuestiona la supuesta progresividad de las leyes de la república posterior a la colonia española - diferenciándose de toda historiografía liberal -, desagrega y evalúa teóricamente el conjunto de posibilidades de basar la transformación de Perú y su transición a una futura organización socialista en el comunismo incaico, con su organización del trabajo cooperativo de la tierra y su comuna agraria. Análogamente a la posición esgrimida por Marx en 1881, Mariátegui cuestiona de este modo la supuesta fatalidad histórica que prescribiría la necesaria destrucción de la comunidad agricola..$^{10}$

En concordancia con el rechazo de la concepción evolucionista de la II Internacional, Mariátegui concibe las producciones culturales, y en especial la literatura, como una clave de interpretación histórica cargada de potencialidades críticas. La importancia de la literatura en el proceso de aprehensión de la Revolución Rusa no supone, sin embargo, una comprensión que surge de la contemplación estética del proceso histórico. Adalbert Dasseu ha indicado como rasgo característico de los intelectuales revolucionarios de la década de 1920 la imbricada relación establecida

10. KOHAN, Néstor, De Ingenieros al Che..., Op. Cit., p. 121 y ss. entre la crítica del presente histórico, los parámetros de acción política y el análisis artístico: “...la toma de conciencia de los intelectuales revolucionarios de entonces se produjo a través de la literatura... Esta fue comprendida como parte esencial de la lucha política..."11

La Revolución Rusa, como expresión del cambio de época que inaugura una nueva perspectiva histórica, cumple un papel determinante en el carácter fundacional de la interpretación de la historia literaria de Mariátegui, en la medida en que la mirada retrospectiva del crítico indaga en la historia con el fin de extraer parámetros de acción acordes a la nueva época que surge con la revolución. En este sentido, la Revolución de Octubre constituye el centro nodal a partir del cual Mariátegui desarrolla su interpretación de la historia de la literatura peruana, y el prisma desde el cual se analiza una época dominada por el avance de la ideologías fascistas, la crisis económica de posguerra, las olas revolucionarias que recorren Europa, así como la particular y decisiva posición que las clases medias adoptan ante la amenaza del evidente proceso de proletarización.

Como exponente de la instauración de un nuevo orden, la Revolución Rusa le ofrece a Mariátegui una de las perspectivas a través de la cual la apariencia caótica de la situación europea de la década de 1920 puede ser contrarrestada. En el amplio marco político,

11. DESSAU, Adalbert, "Literatura y sociedad en las obras de José Carlos Mariátegui”, en MELIS, Antonio, DESSAU, Adalbert, KOSSOK, Manfred, Mariátegui, Tres estudios, Biblioteca Amauta, Lima, 1971, p. 57. Respecto de Mariátegui: "No es exagerado decir que el camino de Mariátegui hacia la revolución pasó en su fase inicial por la literatura”. Ídem, p. 74. 
económico y cultural que se abre con el triunfo de la revolución, la función de la literatura adquiere una centralidad metodológica. Así se observa ya en su artículo dedicado a la lírica de Rainer Maria Rilke (1927), donde Mariátegui advierte el peligro metodológico implícito en la aplicación de "categorías estéticas" en torno al análisis de obras particulares, en la medida en que presupondría, para el crítico, el riesgo de configurar una estructura homogénea, pero abstracta, que no respeta la cualidad de las obras que le sirven de base. El autor de La escena contemporánea, sin embargo, es consciente de que "no se puede prescindir de ellas para enjuiciar con cierto orden la poesía y el arte de esta época caótica. El caos, en la poesía y en el arte, no es nunca tan absoluto como para no aceptar provisoriamente un orden que permita explotarlo y analizarlo". ${ }^{12}$ En otro de los puntos de contacto que mantiene con la lectura de Benjamin, Mariátegui concibe la obra de arte, en tanto mónada sustraída al continuum histórico, como la vía de acceso a una totalidad histórica alternativa, a partir de la cual "se conservan y suprimen en la obra, la obra de vida, en la obra de vida, la época, y en la época, el curso entero de la historia". ${ }^{13} \mathrm{La}$ literatura, así, constituye un órgano de interpretación histórica que excede las particularidades nacionales, en función

12. MARIÁTEGUI, José Carlos, "Rainer Maria Rilke”, en MARIÁTEGUI, José Carlos, Crítica literaria, Jorge Álvarez, Buenos Aires, 1969, p. 187.

13. Michel Löwy ha analizado la aplicación del método benjaminiano en ocasión de su lectura de Las flores del mal, de Charles Baudelaire: "En este escrito, arrancado al curso homogéneo de la historia, se reúne y conserva el conjunto de la obra del poeta; en ella, se reúne y conserva el siglo XIX francés, y en este, 'el curso entero de la historia"'. Cf. LÖWY, Michel, Walter Benjamin. Aviso de incendio. Una lectura de las tesis "Sobre el concepto de historia" (traducción de Horacio Pons), Fondo de Cultura Económica, Buenos Aires, 2002, p. 153. de su capacidad de representar conflictos humanos a partir de acontecimientos históricamente condicionados. En la primera de las conferencias que Mariategui dicta entre 1923 y 1924 en la Federación de Estudiantes (luego de sus años de aprendizaje en Europa), "La crisis mundial y el proletariado peruano", aborda, ya desde su título, la relación que vincula a la crisis europea con la situación política del Perú:

La crisis tiene como teatro principal a Europa; pero la crisis de las instituciones europeas es la crisis de las instituciones de la civilización occidental. Y el Perú... gira dentro de la órbita de esta civilización [que] ha creado entre todos los pueblos lazos materiales que establecen entre ellos una solidaridad inevitable. E1 internacionalismo no es sólo un ideal; es una realidad histórica. ${ }^{14}$

\section{La disputa política en torno a la interpretación literaria.}

"Materia primaria de la unidad de toda fuerza es el idioma... Sólo a partir de la producción de obras propiamente artísticas, de méritos perdurables, en español, italiano y francés, aparecen respectivamente las literaturas española, italiana y francesa". ${ }^{15} \mathrm{La}$ incidencia de la producción literaria en la conformación de la idea de nación le permite a Mariátegui fundamentar una concepción de la historia de la literatura que no se aviene con "la

14. MARIÁTEGUI, José Carlos, "Historia de la crisis mundial”, en Obras...,Op. Cit., p. 228.

15. MARIÁTEGUI, José Carlos; , Siete ensayos..., Op. Cit., p. 180. 
concepción esteticista del arte" ${ }^{16} \mathrm{E} 1$ rechazo de la estética de L'art pour l'art, sin embargo, no supone la filiación con las corrientes de interpretación sociológicas de la literatura, tal como lo expresa la crítica que le dirige a Federico de More en su análisis de la obra de Ricardo Palma. En el abordaje de la literatura peruana que Federico de More desarrolla en Ensayo acerca de las literaturas del Perú (1924), Mariátegui aprecia la presencia simultánea de factores sociológicos (en el marco del cual la literatura "sólo es traducción de un estado político y social") y rasgos esencialistas (tendientes a registrar una sustancia privativa de la literatura nacional) que restringe el potencial crítico de la interpretación; la lectura de More “... estudia los factores raciales y las raíces telúricas de la literatura peruana. Estudia sus colores y sus líneas esenciales; prescinde de sus matices y de sus contornos complementarios. El método es de panfletario; no es de crítico." ${ }^{17}$

En la búsqueda de un método de interpretación que eluda las restricciones que suponen tanto la lectura esteticista como la sociológica, pero que también se corresponda al horizonte de expectativas del lector ideal que proyecta, Mariátegui plantea, de cara al análisis de la particularidad de la literatura peruana, un marco normativo de rasgos generales y provisorio: "Una teoría moderna - literaria, no sociológica - sobre el proceso normal de la literatura de un pueblo distingue en él tres períodos: un periodo colonial, un período cosmopolita, un período nacional... No prevé más esta teoría de la literatura. Pero no nos hace falta, por el momento, un sistema

16. Ídem, p. 180.

17. Ídem, p. 192. más amplio". ${ }^{18} \mathrm{La}$ apelación de Mariátegui al decurso "normal" de la historia de la literatura es relativizada, en su proceso, por el carácter ensayístico del que sirve para postular una clave interpretativa, y no un esquema prefijado al que se deban adecuar de manera forzosa los fenómenos literarios. ${ }^{19}$

La muerte de Mariátegui parece haber clausurado el carácter procesual de su desarrollo intelectual. La evaluación de su labor, en lugar de constatar la pluralidad de ejes que estructura un pensamiento político y estético que no ha alcanzado su madurez, se nutre de aportes que, en su unilateralidad, reducen el análisis de su participación en la vida política del Perú y de su representatividad como intelectual marxista. Considerado un caso cerrado en el marco del desarrollo histórico, la figura de Mariátegui se reduce a ser concebida como la representante de un "marxismo abierto", en el que confluyen tendencias por demás contradictorias (como su lectura en clave marxista de Sorel, de Spengler, o de Bergson); un exponente del populismo político y literario; ${ }^{20}$ responsable del desviacionismo izquierdista del APRA, una vez fundado el Partido Comunista del Perú, ${ }^{21}$ o un stalinista avant la lettre, por

\section{8. Ídem, p.184.}

19. “Ninguno de estos ensayos está acabado: no lo estarán mientras yo viva y piense y tenga algo que añadir a lo por mí escrito, vivido y pensado". Ídem, p. 17.

20. Ver: MIROSCHEVSKI, Vladimir, “El 'populismo' en el Perú. Papel de Mariátegui en la historia del pensamiento social latinoamericano", en ARICÓ, José (editor) Mariátegui y los orígenes del marxismo latinoamericano, Ediciones pasado y presente, México, 1980, pp. 55-70.

21. ARICÓ, José, “Introducción”, en ARICÓ, José (editor) Mariátegui ..., Op. Cit., p. XXVI. 
cuanto se lo reconoce como un precursor del realismo socialista. ${ }^{22}$

En su respuesta a los Siete ensayos de interpretación de la realidad peruana, el teórico católico Víctor Andrés Belaunde, bajo el sintomático título de La realidad nacional (1931), sostiene que la periodización formulada por Mariátegui, en realidad, expresa una mera traducción del "viejo e insostenible cuadro marxista", en función del cual "identifica la literatura colonial con la literatura feudal, literatura cosmopolita con literatura burguesa y literatura nacional con literatura proletaria." ${ }^{23} \mathrm{La}$ desacreditación del método de interpretación, de este modo, se encuentra vinculada con una herencia marxista que Mariátegui retoma, y que lo aleja de la realidad del Perú. Sus críticos harán uso de la relación entre interpretación literaria y lineamiento político, que el mismo Mariátegui se había encargado de poner de relieve desde 1923. Así, el fundador del APRA, Haya de la Torre, hace foco en el presunto carácter europeizante del Amauta, residuo de su estadía en Europa:

"Mariátegui piensa como un intelectual europeo del tiempo en que él estuvo en Europa. Pero la realidad de estos pueblos cambia y exige nuevas tácticas. Mis objeciones fraternales a Mariátegui fueron siempre contra su falta de sentido realista, contra su exceso de intelectualismo y su

22. DESSAU, Adalbert, "Literatura y sociedad en las obras de José Carlos Mariátegui”, en MELIS, Antonio, DESSAU, Adalbert, KOSSOK, Manfred, Mariátegui..., Op. Cit., p. 100.

23. BELAUNDE, Víctor Andrés, Citado en: CARMONA, Julio, "José Carlos Mariátegui y César Vallejo: Los iniciadores”, en CARMONA, Julio, La poesía clasista. Poesía y lucha de clases en el Perú contemporáneo, Windmills Edition, California-USA, 2010, p. 101. ausencia casi total de un sentido eficaz y eficiente de acción." ${ }^{4}$

La intensificación de las críticas alcanza un punto máximo en el marco de la fundación del Partido Comunista del Perú (mayo de 1930), a través de la cual las políticas revolucionarias quedan subsumidas a las directivas de la Internacional Comunista, y la posición de la fracción liderada por Mariátegui es catalogada como una desviación pequeñoburguesa. ${ }^{25}$ En ese marco, Eudocio Ravines, secretario general del PCP, "construirá su liderazgo a partir de la negación sistemática del legado de Mariátegui. El PCP le reprochará a Mariátegui - post-mortem - haber 'sustituido la táctica y la estrategia revolucionaria por el debate o la discusión"”. ${ }^{26}$

En plena crisis del marxismo, en 1984, Ángel Rama afirma que el juicio histórico ya no precisa la cautela que caracterizaba a Mariátegui en relación con los movimientos culturales incipientes, sino que ha llegado la hora de un balance. "Ese balance es adverso", de acuerdo a la lectura de Rama, en la misma medida en que la perspectiva de una cultura y literatura indígenas propuesto por Mariátegui dejaba de lado "la cultura

24. HAYA DE LA TORRE, Citado en ARICÓ, José, "Introducción" en: ARICÓ, José (editor) Mariátegui..., Op. Cit., p. XXVI.

25. "No se trataba de una cuestión de rótulos ni de diferencias 'tácticas'. Existían diferencias de fondo en relación a las alianzas políticas, la composición de clase y los modos de construir el partido. En general la IC, absolutamente desinteresada de la realidad concreta de Nuestra América, no tolera la reivindicación de la autonomía que formula la delegación peruana...". MAZZEO, Miguel, Invitación al descubrimiento. José Carlos Mariátegui y el socialismo de Nuestra América, El Colectivo, Buenos Aires, 2008, p. 41.

26. Ídem, p. 44. 
indígena del presente". ${ }^{27} \mathrm{La}$ inadecuación entre las perspectivas subjetivas y los datos de la realidad concreta radica, desde el punto de vista de Ángel Rama, en la adopción, por parte de Mariátegui, de un marxismo "que en la época se ofreció con rasgos mecánicos y simplistas". ${ }^{28}$

Pero las tentativas por contrarrestar tales acusaciones, en gran medida unilaterales, corren el riesgo de solapar aquellos aspectos problemáticos que hacen a un pensamiento en constante marcha y formación. Así sucede con la analogía y confrontación selectivas con las que se pueda analizar la obra de Mariátegui. En función de esas operaciones, la obra de un autor es rescatada por una equiparación con la de otro sin analizar los motivos problemáticos que puedan compartir; de manera inversa, la obra del autor en cuestión es destacada a partir de una crítica sesgada de la figura con la que se lo confronta.

Un ejemplo del primer caso se advierte en la equiparación de la obra de Mariátegui con la de Benjamin, un autor que, particularmente en Argentina, ha sido objeto de innumerables comparaciones. La razón de estas comparaciones no siempre se halla fundada en una consonancia fundamental, sino en el impulso por lograr que el contacto con el pensamiento de Benjamin contagie la expectativa que despierta el teórico alemán, y redima un pensamiento que se encuentra en disputa. Sin embargo, también la figura de Benjamin se encuentra atravesada por tendencias opuestas. En 1934, Benjamin

27. RAMA, Ángel, Transculturación narrativa en América Latina, Ediciones El Andariego, Buenos Aires, 2007, p. 165.

28. Ídem, p. 166. produce dos ensayos que, en gran medida, divergen en sus perspectivas: El autor como productor, fuertemente influido por las resonancias políticas de la Unión Soviética, y Franz Kafka, en el que la mirada crítica excede los condicionamientos políticos coyunturales. En el primero de los ensayos mencionados, Benjamin intentaba refutar la concepción que, a partir de la tesis de Mannheim, hacía del intelectual el representante de una inteligencia absuelta de las determinaciones sociales, una "capa relativamente sin clase, sin una ubicación demasiado fija”: “...con la toma del poder... la inteligencia debe ir a las fábricas y cumplir allí 'funciones de servicio', las 'que se le asignen". ${ }^{29}$

"La tendencia política correcta incluye una tendencia literaria. $\mathrm{Y}$ añadiremos en seguida: esa tendencia literaria, contenida de manera implícita o explícita en cada tendencia política correcta, es la que constituye, y no otra cosa, la calidad de la obra. Por eso la tendencia política correcta de una obra incluye su calidad literaria, ya que incluye su tendencia literaria." ${ }^{30}$

En su estudio sobre la concepción estéticopolítica de Mariátegui, Fernanda Beigel distingue, de entre los teóricos marxistas influyentes del período, a Gramsci y Benjamin (“...las concepciones de estos dos teóricos fueron objeto de interpretaciones múltiples que enriquecieron el marxismo y revitalizaron

29. MANNHEIM, Karl, citado en WIZISLA, Erdmut, Benjamin y Brecht. Historia de una amistad (traducción de Griselda Mársico), Paidós, Buenos Aires-BarcelonaMéxico, 2007, p. 149 y ss.

30. BENJAMIN, Walter, "El autor como productor", en BENJAMIN, Walter, Tentativas sobre Brecht.

Iluminaciones II. (traducción de Jesús Aguirre), Alfaguara, Madrid, 1998, p. 118. 
la tradición crítica de los 20") ${ }^{31}$, de los modelos que representan Bertolt Brecht y György Lukács, quienes "fueron paradigmáticos en relación con la 'esterilización' del pensamiento estético en la órbita de la III Internacional". ${ }^{32}$ Lukács, de acuerdo a este cuadro, es un exponente de los "grandes intelectuales, que mantuvieron una posición militante en el terreno del comunismo internacional y debieron adecuar sus reflexiones a las estrechas premisas culturales del realismo socialista a partir de 1932-1934". ${ }^{33}$ De este modo, la interpretación del carácter procesual de la obra de Mariátegui se destaca por su dinamismo, pero en el marco de la presentación de imágenes estáticas del pensamiento de aquellas figuras representativas que componen el marco ideológico de la obra del Amauta. En el caso de Lukács, el problema radica, a diferencia de lo que sucede con Mariátegui, en la amplitud del carácter procesual de una obra que recorre gran parte del siglo XX. La imagen que Beigel construye de Lukács no se corresponde con el desarrollo intelectual del filósofo húngaro: la alusión a la teoría del reflejo estético de la realidad que Lukács analiza en seis de los capítulos de La peculiaridad de lo estético son reducidos a la expresión de un compromiso legitimista del "realismo socialista". Esta imagen deja de lado que la mímesis en la que Lukács da cuenta de la reconfiguración estética de la realidad intenta dar con las categorías propias de la esfera estética, que las distinguen de los reflejos científicos, éticos, religiosos, entre otros. E1 carácter antropomórfico del reflejo

31. BEIGEL, Fernanda, El itinerario y la brújula. El vanguardismo estético-político de José Carlos Mariátegui, Biblios, Buenos Aires, 2003, p. 48.

32. Ibídem.

33. Ibídem.

144 estético supone que la realidad a representar no se encuentra acabada, cerrada al individuo que desde una perspectiva externa se encuentra en condiciones de representar "objetivamente", de acuerdo a parámetros científicos; el carácter antropomórfico del arte supone que la realidad representada se compone de elementos propios de la realidad objetiva, pero atravesados, también de manera constitutiva, por factores subjetivos. A partir de esta dialéctica el arte puede dar cuenta de su potencial desfetichizador de la realidad concreta, o de las estéticas prescriptivas:

en el período de consolidación de los principios estalinistas acabó por dominar la costumbre de no dejar que la composición literaria naciera orgánicamente de los destinos singulares individuales llevados a tipicidad, sino, por el contrario y partiendo de una tesis científicamente (o pseudocientíficamente) puesta, escoger las figuras y sus destinos de acuerdo con la tendencia y el contenido de aquella tesis, agruparlos de ese modo, proveerlos de cualidades positivas o negativas, etc. Con eso se rompe la cerrazón estética de las obras y se sustituye por una trascendencia contrapuesta al mundo al que se da forma, con la única diferencia de que esa trascendencia, vista por su contenido, no representa un más allá real, sino una situación terrenal. ${ }^{34}$

La equiparación de la labor crítica de Mariátegui con las disposiciones prescriptivas sobre las que se funda la estética del realismo socialista, formulada por Adalbert Dessau, y llevada a crítica por Fernanda Beigel,

34. Ver: LUKÁCS, György, Estética. La peculiaridad de lo estético, V. IV, (traducción de Manuel Sacristán), Grijalbo, Barcelona, 1966, pp. 58 y ss. y LUKÁCS, György, Estética. La peculiaridad de lo estético, V. II, Grijalbo, Barcelona, 1966, V. II, pp. 530 y ss. 
resulta crucial en el contexto del análisis de la recepción de la literatura rusa por parte de Mariátegui. La afirmación de Dessau según la cual Mariátegui representa al "primer gran teórico marxista-leninista y el fundador de la ciencia y crítica literarias marxistas en América Latina", ${ }^{35}$ sirve de presupuesto para indicar que "la literatura consecuentemente revolucionaria es, para Mariátegui, el realismo socialista que llama realismo proletario. Este concepto aparece por primera vez en 1929, simultáneamente con su formulación en la Unión Soviética". ${ }^{36}$ $\mathrm{El}$ análisis de la recepción de la literatura rusa por parte de Mariátegui, de las vinculaciones que establece entre los planos literario y político, así como del reconocimiento de la problemática autonomía estética en el marco del proceso revolucionario puede ofrecer una clave interpretativa que le haga justicia a su testimonio de parte.

\section{E1 acceso a literario a la Revolución Rusa: la reconfiguración de un modelo}

En su artículo La nueva literatura rusa no iría en itálica (1926) Mariátegui hace foco en la particularidad de una literatura que se torna central en función del proceso revolucionario, pero en el marco de un interés que intenta abordar las diversas corrientes de nuevas literaturas europeas. Así, a los análisis referidos al surrealismo y populismo franceses, a la disputa entre las tendencias rurales y citadinas en la Italia de Mussolini, a la comparación de las manifestaciones que

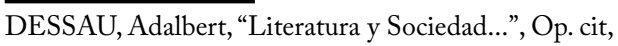
p. 68.

36. Ídem, p. 100. el futurismo expresa en Italia y en Rusia, la reflexión acerca de la nueva literatura rusa retoma la sentencia enunciada por Ehrenburg, que expresa la significación que le otorga a la esfera literaria como expresión del nuevo orden: "los extranjeros que no conocen la nueva literatura rusa no conocen a la nueva Rusia.....37

El foco que Mariátegui coloca sobre las nuevas literaturas europeas incide en la perspectiva literaria y política que se postula en Siete ensayos... Pero la comprensión de la nueva literatura implica, en la interpretación histórica de Mariátegui, el reconocimiento de una herencia cultural. Ese lugar lo ocupa, en el cruce de historicidades que estructura el pensamiento estético de Mariátegui, la imagen de una literatura indígena. El análisis de la literatura indigenista no puede identificarse con una literatura indígena, en la medida en que aquella "es todavía una literatura de mestizos" que "no puede darnos una versión rigurosamente verista del indio. Tiene que idealizarlo y estilizarlo". ${ }^{38}$ Este planteo retoma el diagnóstico que Trotsky desarrolla en Revolución y literatura acerca del arte proletario. En su ensayo Trotski, de 1924, Mariátegui exhibe la influencia que el autor de Literatura y revolución ejerce sobre su propio método de interpretación, que opone a la lectura de la nueva literatura rusa difundida entre los medios de habla hispana. En torno a la cuestión referida a la posibilidad de reconocer un arte proletario, Mariátegui aprueba la sentencia de Trotsky según la

37. MARIÁTEGUI, José Carlos, "La nueva literatura rusa”, en MARIÁTEGUI, José Carlos, Crítica..., Op. Cit., p. 145.

38. MARIÁTEGUI, José Carlos, Siete ensayos..., Op. Cit., p. 257. 
cual "la cultura no es la primera fase de un bienestar: es un resultado final": 39 "El orden nuevo es todavía demasiado embrionario e incipiente. Se encuentra en un período de formación. Un arte del proletariado no puede aparecer aún. Trotsky define el desarrollo del arte como el más alto testimonio de la vitalidad y del valor de una época". ${ }^{40}$

La perspectiva en el Perú encuentra un reconfiguración original del modelo ruso:

Este indigenismo que está solo en un período de germinación... podría ser comparado - salvadas todas las diferencias de tiempo y de espacio - al 'mujikismo' de la literatura rusa pre-revolucionaria. El 'mujikismo' tuvo parentesco estrecho con la primera fase de la agitación social en la cual se preparó e incubó la revolución rusa. La literatura 'mujikista' llenó una misión histórica. Constituyó un proceso del feudalismo ruso, del cual salió éste inapelablemente condenado. La socialización de la tierra, actuada por la revolución bolchevique, reconoce entre sus pródromos la novela y la poesía 'mujikistas'. ${ }^{41}$

La refundación política y cultural que supone la revolución rusa implica el reconocimiento de una tradición que se opone a la difundida por los críticos burgueses como representante de la nueva literatura rusa. Así se aprecia en su artículo La Rusia de Dostoievski. A propósito del libro de Stefan Zweig (1929), donde se oponen los polos que representan Tolstoi

39. MARIÁTEGUI, José Carlos, “Trotsky”. Disponible en: <https://www.marxists.org/espanol/mariateg/oc/ la_escena_contemporanea/paginas/trotsky.htm>.

40. Ibídem.

41. MARIÁTEGUI, José Carlos, Siete ensayos..., Op. Cit., p. 252s.

146 y Dostoievski, una vez más retomando la lectura de Ehrenburg, quien "desmintió esta influencia, afirmando que las actuales generaciones rusas estaban, precisamente, lo más distantes posibles de Dostoievski y que, en la nueva Rusia, era mucho más evidente y neta la presencia de Tolstoy". ${ }^{42}$ La línea conformada por "Dostoievski, Andreyev, Sollogub" representa la incapacidad de una burguesía frustrada, que no logró imponer sus demandas ante un poder técnico y financiero que dependía, bajo el régimen absolutista, de fuerzas extranjeras. En la obra de Dostoievski, Mariátegui, reconoce un romanticismo que surge de la posición aislada de una inteligencia impotente, "un utopismo desorbitado, en que el más extremista y disolvente individualismo se asociaba al mesianismo racial, hostil a Europa...". ${ }^{43}$ A esta línea evolutiva Mariátegui le opone la que, partiendo de Tolstoi, el configurador épico de la vida campesina, y a través del novelista crítico de la vida burguesa, Gorki, alcanza en la novela El cemento (1925) de

42. MARIÁTEGUI, José Carlos, "La Rusia de Dostoievski. A propósito del libro de Stefan Zweig”, en MARIÁTEGUI, José Carlos, Crítica..., Op. Cit., p. 249 y ss. Las consideraciones acerca de la figura de Tolstoi y Dostoievski no se concentra en el análisis de sus obras, sino en el plano de la recepción; en este sentido, la tarea de Mariátegui consiste en evaluar la crítica literaria que desde el plano de la burguesía occidental se ejerce sobre la literatura rusa previa a la Revolución, como sobre la nueva literatura rusa. La crítica literaria burguesa con la que confronta Mariátegui, por ejemplo, a través de los escritos de Luis de Zulueta, discípulo de José Ortega y Gasset, hacía de Dostoievski el precursor de una Revolución Rusa a la que se le adjudican rasgos místicos: "El misticismo, la neurosis, la exasperada búsqueda de infinito y de absoluto, que hallan su más fuerte y patética expresión artística en la obra de Dostoievski, eran estimados como los factores morales de la Revolución..." Ídem, p. 249.

43. Ídem, p. 250. 
Gladkov la representación épica del proceso revolucionario. Esta confrontación, que busca instalar una línea de continuidad entre la nueva literatura rusa que representa Gladkov y la tradición épica de un Tolstoi, ${ }^{44}$ por otro lado relativiza la imagen de Mariátegui como un defensor unilateral de las vanguardias literarias.

De este modo, Mariátegui se hace eco del pronóstico de Literatura y revolución de Trotski (y que ya en el contexto de la Primera Guerra Mundial, György Lukács había esbozado en las páginas finales de Teoría de la novela - 1914, publicado en 1920 -, capítulo introductorio del proyectado, e inconcluso, estudio sobre la obra de Dostoievski) acerca del carácter épico de la literatura fundacional en el marco del cambio de época: "Uno de los rasgos más característicos de la nueva literatura rusa es su épica. El género épico, que en Occidente ha muerto, en Rusia resucita renovado". ${ }^{45} \mathrm{La}$ influencia de Trotski se advierte en su artículo sobre el poeta Essenin, donde transcribe y parafrasea la hipótesis de Trotski según la cual el carácter lírico de la obra del poeta se contrapone a la épica del período revolucionario. ${ }^{46} \mathrm{El}$ pretendido

44. "El Cemento pertenece a esta nueva literatura, que en Rusia tiene precursores desde Tolstoy y Gorki... La novela de Gladkov supera a las que la han precedido en la traducción, en que nos revela, como ninguna otra, la revolución misma." En MARIÁTEGUI, José Carlos, "Elogio de El cemento y del realismo proletario" Disponible en: <https://www.marxists.org/espanol/ mariateg/oc/el_alma_matinal/paginas/elogio\%20al\%20 cemento.htm\#1a>.

45. MARIÁTEGUI, José Carlos, "La nueva literatura rusa”, en MARIÁTEGUI, José Carlos, Crítica..., Op. Cit., p. 148 y ss.

46. "Esenin era un ser interior, tierno, lírico; la revolución, en cambio, es pública, épica...”. En TROTSKI, León, Literatura y revolución. Escritos sobre arte y cultura, escritores carácter épico que la revolución porta, en tanto acontecimiento fundacional, también guarda una estrecha relación con una herencia teórica occidental. Hegel ha distinguido como aspectos centrales de la épica la configuración poética de una comunidad y del héroe positivo que se desarrolla en su marco. En este contexto, la acción que lleva adelante el héroe de la épica responde a una ética comunitaria que se expresa bajo la apariencia de la libertad individual. ${ }^{47}$

La representación poética de la comunidad, sin embargo, supone el desarrollo de la comunidad sensible. En sus Lecciones sobre estética, Hegel afirma que no

debemos representarnos la cosa como si ya en su edad heroica como tal, la cuna de su epos, poseyese un pueblo el arte de poderse describir poéticamente a sí mismo; pues una cosa es una nacionalidad en sí poética en su ser-ahí efectivamente real, y otra distinta la poesía como la consciencia representativa de temáticas poéticas y como representación artística de un mundo tal...Homero y los poemas que

y crítica literaria (estudio introductorio de Isidoro Cruz Bernal), s/d traducción, Antídoto, Buenos Aires, 2004 p. 263.

47. "Las relaciones de la vida ética... deben haberse descubierto, estructurado y desarrollado, pero en cambio todavía no basta la forma de máxima, deberes y leyes universales, válidos también para sí sin la viva particularidad subjetiva de los individuos y que poseen también la fuerza de afirmarse contra la voluntad individual... De modo que en el epos encontramos ciertamente la comunidad sustancial de la vida y la acción objetivas, pero igualmente la libertad en este vivir y actuar, que parece derivar enteramente de la voluntad subjetiva de los individuos". HEGEL, Friedrich, Lecciones sobre estética (traducción de Alfredo Brotóns Muñoz), Akal, Madrid, 1989, p. 758. 
llevan su nombre son dos siglos posteriores a la guerra de Troya... ${ }^{48}$

En concordancia con esta concepción según la cual la representación artística (más allá de los elementos anticipatorios que Mariátegui le reconoce) sucede al desarrollo histórico, la interpretación de la obra de Gorki de Mariátegui procura, por un lado, identificar su obra como propia del período anterior a la revolución, por otro, desligarlo de la imagen de Gorki que presenta la crítica occidental como un crítico de la revolución.

En el artículo Los Artomonov, novela de Máximo Gorki (1928) Mariátegui confronta, una vez más, con la lectura occidental que hace de la impotencia social un antecedente de la revolución: “... ni el asunto ni los personajes de Los Artamonov tienen algo que ver con el comunismo. Las tres generaciones de la familia Artamonov que nos presenta Gorki son tres generaciones burguesas". ${ }^{49} \mathrm{El}$ período que Gorki representa ("Desde la abolición de la servidumbre hasta la Revolución Bolchevique") expresa la incapacidad de la burguesía rusa de imponer un régimen democrático burgués: "Los Artamonov son una familia burguesa: espécimen de una burguesía retardada, provinciana, alcohólica, cuya existencia histórica empezó en 1861 con la abolición de la servidumbre y que no alcanzó jamás a imponer a Rusia su doctrina ni su régimen". ${ }^{50}$

El hecho de que en la caracterización de

48. Ídem, p. 754.

49. MARIÁTEGUI, José Carlos, “'Los Artomonov', novela de Máximo Gorki”, en MARIÁTEGUI, José Carlos, Obras..., Op. Cit., pp. 369-375.

50. Ibídem.
Gorki (“... ondulante, inquieto, heterodoxo, no ha seguido rígidamente ningún programa y ninguna confesión política") ${ }^{51}$ se puedan reconocer rasgos que se han atribuido al mismo Mariátegui no debe sorprender, ya que en el análisis de la literatura rusa Mariátegui lleva a cabo una autoevaluación de su desarrollo intelectual que excede la autocrítica referida a su "edad de piedra": su inicial tendencia al esteticismo. ${ }^{52}$ Como el autor de La madre, Mariátegui atestigua en el proceso de la literatura a partir de las experiencias que recabó en la convulsionada Europa de principios de los años veinte. Mariátegui encuentra en Gorki a un testigo que (así como Lenin ha definido la obra de Tolstoi como un espejo de la revolución), ${ }^{53}$ tras la corroboración de la decadencia de las sociedades occidentales, se compromete con el pedagógico proceso revolucionario que se lleva adelante en Rusia.

51. MARIÁTEGUI, José Carlos, "Máximo Gorki y Rusia”, en Obras..., Op. Cit., p. 372.

52. “...cuando Mariátegui las emprende contra los que todavía se sienten deslumbrados por la literatura de Andréiev y Arzibachev quizás también está terminando de ajustar cuentas consigo mismo o, mejor, con lo que aún queda de su denominada «edad de piedra»". ARROYO REYES, Carlos Eduardo, "Mariátegui, Amauta y la literatura rusa de la revolución”. Disponible en:

<http://www.librosperuanos.com/autores/ articulo/00000001226/Mariategui-Amauta-y-laliteratura-rusa-de-la-revolucion>.

53. De acuerdo a la lectura de Lenin, la postura de Tolstoi se encuentra atravesada, por un lado, por la activa protesta contra la explotación, y, por otro, por la doctrina de la no resistencia al mal, que implica la afirmación del servilismo: "Las contradicciones en las ideas de Tolstoi... son un verdadero espejo de las condiciones contradictorias en las cuales se desenvolvía la actividad histórica del campesinado en el transcurso de nuestra revolución". Ver: LENIN, Vladimir Ilich, STALIN, José, Sobre la literatura y el arte (traducción de Alicia Ortiz), Editorail Calomino, La Plata, 1946, p. 59. 
El texto fuente sobre el que se elabora la confluencia, postulada y citada por Dessau y criticada por Beigel, entre lo que Mariátegui denomina realismo proletario y el realismo socialista lo constituye la reseña crítica de Mariátegui "Elogio de El cemento y del realismo proletario" (marzo-noviembre de 1929) en la que analiza la novela El cemento (1925), de Feodor Gladkov (1883-1958), y que debe considerarse en el contexto del proceso que Mariátegui advierte abierto. Mariátegui sostiene que la novela de Gladvok no constituye una novela de propaganda política, sino una novela realista que contrasta con el realismo populista de la nueva literatura francesa, heredera del naturalismo de Zola, así como con la imposibilidad de la burguesía por dar forma a un arte realista, dado el carácter apologético de una tendencia a ocultar o expulsar aspectos centrales de una realidad que se caracteriza por su universalismo. Frente a la "optimista y rosada pedagogía de pequeños burgueses”, la novela de Gladkov configura un proceso histórico que desarticula el componente ideológico que se oculta detrás de la noción de familia, sociedad y Estado burgueses. ${ }^{54} \mathrm{La}$ representación de lo "sublime proletario" (Sorel) que Mariátegui reconoce en El cemento, por el contrario, da cuenta de la desarticulación de los ideales burgueses, que restringen a los personajes a ser portavoces de estructuras sociales bajo las cuales se reprime el potencial humano (ética burguesa, familia, patriarcalismo). En la novela, de acuerdo

54. "El rechazo del marxismo, parecido en su origen y proceso, al rechazo del freudismo... que no consiente a la literatura burguesa liberarse de su tendencia a la idealización de los personajes, los conflictos y los desenlaces". MARIÁTEGUI, José Carlos, "Elogio de El cemento y del realismo proletario". Disponible en: <https://www.marxists.org/espanol/mariateg/oc/ el_alma_matinal/paginas/elogio\%20al\%20cemento. htm\#1a>. a la lectura de Mariátegui, se asiste a la representación de la transformación humana que atraviesan los personajes en el contexto de la revolución.

La mención de los aspectos biográficos, que Mariátegui recoge de la crítica de Julio Âlvarez del Vayo, busca justificar el modo en que la obra del autor se abrió camino en un contexto adverso, hasta alcanzar una configuración del proceso revolucionario que crece con el desarrollo de Gladkov como autor. En la reseña, esta tendencia se opone al adoctrinamiento que desde el Partido, a partir del Decreto de 1932, se proclama "desde arriba". El carácter prescriptivo y restrictivo de la Disposición del Comité Central del Partido Comunista de los Bolcherviques de la Unión Soviética sobre la Reconstrucción de las Organización Literarias y Artisticas, ${ }^{55}$ que se consolida en 1934 con la intervención de Zhdanov en el "1er Congreso de la Unión de Escritores de la URSS" clausura la tendencia que Mariátegui reconocía como posible desarrollo de la nueva literatura rusa. Pues

55. "En la actualidad, cuando ya han tenido tiempo de crecer los cuadros de la literatura proletaria y del arte... los marcos de las organizaciones literarias y artísticas de carácter proletario existentes se han quedado estrechos y frenan el auténtico alcance de la creación artística. Esta circunstancia conlleva el riesgo de que dichas organizaciones, de ser un medio para la mayor movilización de los escritores y artistas soviéticos en torno a la tarea de la construcción socialista, pasen a convertirse en un medio para el cultivo del aislamiento en círculos apartados de los deberes políticos contemporáneos y de los grupos significativos de escritores y artistas participantes en la construcción socialista". Ver: PARTIDO COMUNISTA DE LOS BOLCHEVIQUES DE LA UNIÓN SOVIÉTICA, "Disposición del Comité Central sobre la reconstrucción de las organizaciones literarias y artísticas", en GÓMEZ, Juan José (editor) Crítica, Tendencia y Propaganda: textos sobre arte y comunismo, 1917-1954, Doble J, S. L., Sevilla, 2004, p. 40. 
si bien Zhdanov coincide con la lectura que Mariátegui retoma de Trotski, de acuerdo con la cual "la decadencia y descomposición de la literatura burguesa, derivadas de la decadencia y corrupción del sistema capitalista, representan el rasgo característico, la particularidad propia de la situación en que se encuentran la cultura y la literatura burguesas en el momento presente", ${ }^{56}$ no reconoce en la literatura rusa sino un atraso respecto de las condiciones materiales que ofrece la revolución. En este sentido, las directivas propuestas por los dictámenes del realismo socialista parecen guardar una relación con el populismo literario que Mariátegui critica como representación superficial y acrítica de una estabilidad social: "Se han creado todas las condiciones necesarias a fin de que la literatura soviética pueda producir obras que respondan a las exigencias culturales de las masas crecientes" ${ }^{57}$ La pretendida adecuación de la representación literaria con las exigencias de las masas parece corresponderse con la imagen que Mariátegui ofrece del populismo francés, que cae en la trampa de abastecer "al pueblo de una literatura que se adapte a sus gustos e indague con simpatía sus sentimientos". ${ }^{58}$

La lectura de Mariátegui, por el contrario, aquí en concordancia con los postulados vanguardistas, $^{59}$ propulsores de una

56. ZHDANOV, Andrei, "La literatura soviética es la más ideológica, la más vanguardista del mundo”, en GÓMEZ, Juan José (editor) Crítica..., Op. Cit., p. 74.

57. Ídem, p.77.

58. MARIÁTEGUI, José Carlos, "Populismo y estabilización capitalista”, en Crítica literaria..., Op. Cit., p. 283.

59. "Pero Mariátegui va más allá de la simple tolerancia, opta claramente por la libertad de la búsqueda intelectual y favorece con igual seguridad, en su ruptura con los métodos de representación tradicionales que se adaptan a los presupuestos ideológicos de la sociedad burguesa en decadencia, reconoce en la novela de Gladkov la configuración de un proceso transformador alternativo de la realidad que, anclado en una tradición, apunta a una perspectiva liberadora: "se puede predecir que El Cemento alcanzará pronto la misma difusión de Tolstoy, Dostoyevsky, Gorky". ${ }^{60}$

Otro clave sintomática de la lectura de Mariátegui se encuentra en la analogía que reconoce entre la novela de Gladkov y Manhattan Transfer (1925), la novela de John Dos Passos. También la novela de John Dos Passos es presentada como exponente de una nueva literatura, en este caso norteamericana. Como en El cemento, en la novela de Doss Passos no se retrata la vida individual, sino "una muchedumbre de vidas que se mezclan, se rozan, se ignoran, se agolpan”. ${ }^{61}$ La técnica narrativa expresa, de acuerdo a Mariátegui, una continuación y renovación del realismo del siglo XIX. Ya no se trata de personajes, sino de lo que les sucede como

praxis de organizador cultural, los movimientos y las expresiones de vanguardia. En las raíces de esta opción están la conciencia aguda de los daños provocados por la escisión entre la vanguardia política y la vanguardia cultural y la consiguiente negación a avalar cualquier deformación propagandista o populista de la literatura. Es Mariátegui quien escribe uno de los primeros ensayos latinoamericanos sobre Joyce, quien sigue con agudeza excepcional la obra de Rilke, de Essenin, de Breton, de Valle Inclán, etc." MELIS, Antonio, "Mariátegui. Primer marxista de América”, en MELIS, Antonio; DESSAU, Adalbert; KOSSOK, Manfred, Mariátegui..., Op. Cit., p. 48 .

60. MARIÁTEGUI, José Carlos, "Elogio de El cemento y del realismo proletario". Op. Cit.

61. MARIÁTEGUI, José Carlos, “Manhattan Transfer, por John Dos Passos”, en Crítica literaria..., Op. Cit., p. 259. 
víctimas de la estructura del modelo de la ciudad del futuro capitalista: “... el verdadero protagonista no es Jimmy sino Manhattan misma". ${ }^{62}$ Pero el desarrollo que presenta la novela norteamericana revela el proceso de deshumanización a la que son sometidos los personajes, que se perciben a sí mismos presas de una dinámica social en la que su individualidad se asemeja a un "juguete mecánico, hueco por dentro": ${ }^{63}$ en la Octava Avenida, los halos de luz que se desprenden de los letreros luminosos disuelven los contornos subjetivos de los individuos:

Las luces brillaban mortecinas a través de ella, las caras se esfumaban, se perfilaban en silueta y desaparecían como peces en un acuario turbio... ${ }^{64}$

Manhattan Transfer es la prueba de que el realismo no ha muerto ... También, bajo este aspecto, hace pensar en $E l$ cemento. Pero mientras El cemento, en su realismo, tiene el acento de una nueva épica, en Manhattan Transfer, reflejo de un magnífico e imponente escenario de una vida cuyos impulsos ideales se han corrompido y degenerado, carece de esta contagiosa exaltación de masas creadoras y heroicas. ${ }^{65}$

Si en El cemento, el proceso que desarticula la individualidad de los personajes representa el acceso a una realidad superadora, en Manhattan Transfer, la utopía es expulsada de la gran ciudad capitalista con el barco en que

62. Ídem, p. 260.

63. Ídem, p. 264.

64. Citado en MARIÁTEGUI, José Carlos, “Manhattan

Transfer, por John Dos Passos”, en Crítica literaria...,

Op.. Cit. p. 265.

65. Ídem, p. 261. son deportados los inmigrantes ("la única voz de esta esperanza"), ${ }^{66}$ en función de un orden social atomizado.

La perspectiva de Mariátegui acerca de la nueva literatura rusa no se ha cumplido; mientras las novelas de la generación perdida (entre la que se encuentra John Dos Passos) han marcado la narrativa del siglo veinte, la perspectiva de $E l$ cemento, en tanto expresión del realismo socialista, ha quedado relegada en el canon literario como materia de estudio de especialistas. Los derroteros de la autonomía literaria, así, parecen guardar una relación problemática con el decurso histórico, a tal punto que la autonomía abre la posibilidad de que solo la representación de la deshumanización alcance una persistencia histórica. Pero el sentido de la historia que se percibe en los destinos de ambas novelas se corresponde con un decurso histórico del que el mismo Mariátegui es, constantemente, desplazado.

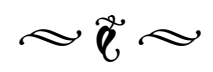

Recibido: 24-04-2017

Aceptado: 28-09-2017

Publicado: 05-12-2017

66. Ídem, p. 266. 


\section{Bibliografía}

ARICÓ, José (editor) Mariátegui y los orígenes del marxismo latinoamericano, Ediciones Pasado y Presente, México, 1980.

ARROYO REYES, Carlos Eduardo, "Mariátegui, Amauta y la literatura rusa de la revolución”.

Disponible en: <http://www.librosperuanos.com/autores/articulo/00000001226/Mariategui-

Amauta-y-la-literatura-rusa-de-la-revolucion>.

BEIGEL, Fernanda, El itinerario y la brújula. El vanguardismo estético-politico de José Carlos Mariátegui, Biblios, Buenos Aires, 2003.

BENJAMIN, Walter, "El autor como productor", en Tentativas sobre Brecht. Iluminaciones II. (traducción de Jesús Aguirre), Alfaguara, Madrid, 1998, pp. 115-134.

BENJAMIN, Walter, "Sobre el concepto de historia” (traducción de Tomás Joaquín Bartoletti y Julián Fava), en Estética y politica, Prefacio de Ralph Buchenhorst, Las Cuarenta, Buenos Aires, 2009, pp. $135-158$.

CARMONA, Julio, "José Carlos Mariátegui y César Vallejo: Los iniciadores", en La poesía clasista. Poesía y lucha de clases en el Perú contemporáneo, Windmills Edition, California-USA, 2010, pp. 91-113.

DESSAU, Adalbert, "Literatura y sociedad en las obras de José Carlos Mariátegui”, en MELIS, Antonio, DESSAU, Adalbert, KOSSOK, Manfred, Mariátegui. Tres estudios, Biblioteca Amauta, Lima, 1971.

FIGUEROA, Noelia, "Walter Benjamin y José Carlos Mariátegui: gestos para refundar una teoría crítica subalterna”, en Herramienta, Buenos Aires, 2012, No 51, pp. 53-68.

GÓMEZ, Juan José (editor) Crítica, Tendencia y Propaganda: textos sobre arte y comunismo, 1917-1954, Doble J, S. L., Sevilla, 2004.

HEGEL, Friedrich, Lecciones sobre estética (traducción de Alfredo Brotóns Muñoz), Akal, Madrid, 1989.

KOHAN, Néstor, De Ingenieros al Che. Ensayos sobre el marxismo argentino y latinoamericano, Instituto Cubano de Investigación Cultural Juan Marinello, La Habana, 2008, pp. 113-128.

LENIN, Vladimir Ilich, STALIN, José, Sobre la literatura y el arte (traducción de Alicia Ortiz), Editorial Calomino, La Plata, 1946.

LÖWY, Michael, Redención y utopia. El judaísmo libertario en Europa Central. Un estudio de afinidad electiva (trad. de Horacio Tarcus), El cielo por asalto, Buenos Aires, 1997.

LÖWY, Michael, Walter Benjamin. Aviso de incendio. Una lectura de las tesis "Sobre el concepto de historia" (traducción de Horacio Pons), Fondo de Cultura Económica, Buenos Aires, 2002.

LUKÁCS, György, Estética. La peculiaridad de lo estético V.IV (traducción de Manuel Sacristán), Grijalbo, Barcelona, 1966. 
MARIÁTEGUI, José Carlos, Crítica literaria, Jorge Álvarez, Buenos Aires, 1969.

MARIÁTEGUI, José Carlos, Obras, 2 volúmenes, Casa de las Américas, La Habana, 1982.

MARIÁTEGUI, José Carlos, Siete ensayos de interpretación de la realidad peruana, (estudio preliminar de María Pía López), Gorla, Buenos Aires, 2005.

MARIÁTEGUI, José Carlos, “Trotsky”. Disponible en: <https://www.marxists.org/espanol/mariateg/ oc/la_escena_contemporanea/paginas/trotsky.htm>.

MARIÁTEGUI, José Carlos, "Elogio de El cemento y del realismo proletario”. Disponible en: <https:// www.marxists.org/espanol/mariateg/oc/el_alma_matinal/paginas/elogio\%20al\%20cemento. htm\#1a>.

MAZZEO, Miguel, Invitación al descubrimiento. José Carlos Mariátegui y el socialismo de Nuestra América, El Colectivo, Buenos Aires, 2008.

RAMA, Ángel, Transculturación narrativa en América Latina, Ediciones El Andariego, Buenos Aires, 2007.

TROTSKI, León, Literatura y revolución. Escritos sobre arte y cultura, escritores y crítica literaria (estudio introductorio de Isidoro Cruz Bernal; s/d traducción), Antídoto, Buenos Aires, 2004.

WIZISLA, Erdmut, Benjamin y Brecht. Historia de una amistad (traducción de Griselda Mársico), Paidós, Buenos Aires-Barcelona-México, 2007. 